\title{
Role of angiotensin II-induced rapid response genes in the regulation of enzymes needed for aldosterone synthesis
}

\author{
Edson F Nogueira, Yewei Xing, Claudia A V Morris and William E Rainey \\ Department of Physiology, Medical College of Georgia, 1120 15th Street, CA Building, Room 3094, Augusta, Georgia 30912, USA \\ (Correspondence should be addressed to W E Rainey; Email: wrainey@mail.mcg.edu)
}

\begin{abstract}
Aldosterone is principally synthesized in the zona glomerulosa of the adrenal by a series of enzymatic reactions leading to the conversion of cholesterol to aldosterone. Angiotensin II (Ang II) is the major physiological regulator of aldosterone production acting acutely to stimulate aldosterone biosynthesis and chronically to increase the capacity of the adrenals to produce aldosterone. We previously defined eight transcription factors that are rapidly induced following Ang II treatment using three in vitro adrenocortical cell models. Herein, we investigated the function of these transcription factors in the regulation of the enzymes needed for aldosterone production. H295R adrenal cells were co-transfected with expression vectors for each transcription factor and promoter/reporter constructs prepared for genes encoding the enzymes needed for aldosterone production. NGFI-B family members induced promoter activity of 3-betahydroxysteroid-dehydrogenase type 2 (HSD3B2), 21-hydroxylase (CYP21A2), and aldosterone synthase (CYP11B2). The importance of NGFI-B in the regulation of CYP11B2 was also demonstrated by reduced CYP11B2 transcription in the presence of a dominant-negative-NGFI-B. A pharmacological approach was used to characterize the Ang II pathways regulating transcription of NGFI-B family genes. Transcription of NGFI-B members were decreased following inhibition of Ang II type 1 receptor (AT1R), protein kinase C (PKC), calcium/calmodulin-dependent kinases (CaMK), and Src tyrosine kinase (SRC). Taken together, these results suggest that Ang II binding to the AT1R increases activity of PKC, CaMK, and SRC, which act to increase expression of the family of NGFI-B genes as well as CYP11B2. Ang II induction of the NGFI-B family members represents an important pathway to increase the capacity of adrenal cells to produce aldosterone.
\end{abstract}

Journal of Molecular Endocrinology (2009) 42, 319-330

\section{Introduction}

Angiotensin II (Ang II) is a major regulator of salt and water balance through regulation of aldosterone synthesis in the zona glomerulosa of the adrenal cortex. Aldosterone biosynthesis is regulated at two steps: 1) an early rate-limiting step that involves the transport of cholesterol into the mitochondria via the action of steroidogenic acute regulatory (StAR) protein and, 2) a late rate-limiting step that involves conversion of corticosterone to aldosterone by the enzyme CYP11B2 (Quinn \& Williams 1988, Muller 1995). StAR is stimulated by Ang II both in vitro (Tremblay et al. 1992, Clark et al. 1995, Cherradi et al. 1997, Betancourt-Calle et al. 2001) and in vivo (Peters et al. 1998, Lehoux et al. 1999). Ang II also stimulates the expression of steroidogenic enzymes in vitro, which are involved in subsequent steps of aldosterone synthesis, including cholesterol side-chain cleavage (SCC or CYP11A1; Bird et al. 1996), HSD3B2 (Rainey et al. 1991), and CYP21A2 (Bird et al. 1998). Finally, Ang II stimulates the last regulatory step in the control of aldosterone production: the transcription of
CYP11B2, an enzyme almost uniquely localized in the zona glomerulosa of the adrenal gland (Shibata et al. 1991, Adler et al. 1993, Clyne et al. 1997).

Adrenal glomerulosa cell stimulation occurs predominantly through Ang II activation of Ang II type 1 receptor (AT1R) via a q-subunit of G-protein coupled receptors $\left(G_{\mathrm{q}}\right)$, activation of inositol trisphosphate/ $\mathrm{Ca}^{2+}$ signaling and protein kinase $\mathrm{C}$ (PKC) isoforms (Hunyady \& Catt 2006). G-protein stimulation also leads to activation of calcium/calmodulin-dependent kinases (CaMK; Chabre et al. 1995, Cote et al. 1998), and mitogen-activated protein kinase (MAPK) members, such as mitogen-activated protein kinase and kinaseextracellular signal-regulated kinase 1 and 2 (MEKERK1/2). Ang II can also act through G proteinindependent pathways including $\beta$-arrestins, tyrosine kinases, and Janus kinase (JAK)/signal transduction and activators of transcription pathways (Seta et al. 2002, Thomas \& Qian 2003, Wei et al. 2003, Miura et al. 2004). Ang II activation of diverse signaling pathways culminates with rapid induction of adrenal cell transcription for numerous response genes (Romero et al. 2004, Nogueira et al. 2007). Herein, we extend our

DOI: 10.1677/JME-08-0112 Online version via http://www.endocrinology-journals.org 
earlier study that defined the transcription factors regulated by Ang II stimulation in adrenocortical cell models from three different species: human, bovine, and rat (Nogueira et al. 2007). The common genes across these three species include eight transcription factors: members of the nuclear receptor superfamily/ nerve growth factor-induced (NGFI-B) family (NGFI-B (also named NR4A1), NURR-1 (also named NR4A2), and NOR-1 (also named NR4A3)), members of the AP-1 complex (FOS, FOSB, and JUNB), the early growth response gene 1 (EGR1), and the activating transcription factor 3 (ATF3; Nogueira et al. 2007). These findings confirm the studies performed by Romero et al. (2004), who have also studied Ang II responsive genes in H295R cells. In the present study, we examined the role of these transcription factors in the regulation of the enzymes involved in adrenal aldosterone synthesis. In addition, we investigated the Ang II intracellular signaling pathways that control transcription of the NGFI-B genes. We showed that Ang II, through activation of PKC, CaMK, and Src tyrosine kinase (SRC) signaling increased expression of the three members of the NGFI-B transcription factor family which were able to enhance transcription of enzymes needed for the final three steps of the aldosterone biosynthesis pathway.

\section{Materials and methods}

\section{Cell culture and treatments}

H295R human adrenocortical tumor cells were cultured in DME/Ham's F12 medium (Invitrogen) and supplemented with $10 \%$ cosmic calf serum (Hyclone, Logan, UT, USA), $1 \%$ penicillin/streptomycin (Invitrogen) and $0.01 \%$ gentamicin (Invitrogen). Cells were maintained in a $37^{\circ} \mathrm{C}$ humidified atmosphere $\left(5 \% \mathrm{CO}_{2}\right)$. For experiments, cells were subcultured onto 12 well cultured dishes (Corning Costar, Corning, NY, USA) at a density of $4 \times 10^{5}$ cells/well for subsequent transfection.

H295R-TR, an adrenal cell line containing a tetracycline response system, was generously provided by $\mathrm{Dr}$ Enzo Lalli (Doghman et al. 2007). Dominant-negative (DN)-NGFI-B was produced by truncating the $5^{\prime}$ transactivation region of the human NGFI-B sequence. DN-NGFI-B, lacking 78 to $1099 \mathrm{bp}$ from the full-length NGFI-B cDNA, encoded a variant protein without the transactivation domain. This protein exhibits normal DNA binding capacity without mediating transcriptional activation, thus acting as an inhibitor for all three subfamily members: NGFI-B, NURR-1, and NOR-1. For generation of H295R-TR stably expressing DN-NGFI-B (H295R-TR-DN), cDNA of DN-NGFI-B was amplified by PCR with forward and reverse primers: $5^{\prime}$-CACCATGT
CAACCAAGGCCCG-3' ${ }^{\prime}$ and $5^{\prime}$-GAGAGTGCGCATGTGCACACG-3' respectively. The PCR product was ligated into the Invitrogen pLENTI6/V5 TOPO vector (Invitrogen) and packaged into a virus construct using Invitrogen's ViraPower Lentiviral Gateway Expression System (Invitrogen). Briefly, 293T cells were co-transfected with the pLENTI6/V5 TOPO vector with ligated DN-NGFI-B gene and packaging vectors for $6 \mathrm{~h}$ using Transfast (Promega) according to manufacturer instructions. Transfection was stopped by adding $2 \times$ low serum medium $(0.2 \%$ cosmic calf serum $+2 \%$ penicillin/streptomycin and $0.02 \%$ gentamicin). Twelve hours later the medium was substituted with growth medium for $2 \mathrm{~d}$ to allow virus packaging. The medium was then collected for further infection. H295R-TR cells were infected overnight with a 1:2 dilution of virus containing medium harvested from 293T cells and stayed in antibiotic-free growth medium for another $24 \mathrm{~h}$. Further antibiotic selection with $200 \mu \mathrm{g} / \mathrm{ml}$ zeocin (Gemini, West Sacramento, CA, USA) was done for 3 weeks. In this study, we used a mixed population of cells containing a tetracyclineregulated DN-NGFI-B. Doxycycline (tetracycline ana$\log$ ) was used at a concentration of $0.25 \mu \mathrm{g} / \mathrm{ml}$ to control the expression of integrated genes. H295RTR-DN cells were cultured in DME/Ham's F12 medium (Invitrogen) and supplemented with $10 \%$ cosmic calf serum (Hyclone), $1 \%$ penicillin/streptomycin (Invitrogen), $0 \cdot 01 \%$ gentamicin (Invitrogen), $5 \mu \mathrm{g} / \mathrm{ml}$ blasticidin (Invitrogen), 1\% insulin-transferrin-selenous acid (BD Biosciences, Bedford, MA, USA). Cells were subcultured onto 24-well culture dishes (Corning Costar) at a density of $2 \times 10^{5}$ cells/well for subsequent treatment. Cells were incubated for $6 \mathrm{~h}$ with or without $10 \mathrm{nM}$ Ang II. Twelve hours prior to treatment, the H295-TR cells were maintained overnight in $1 \times$ low serum medium (DMEM/F12 medium supplemented with $0 \cdot 1 \%$ Cosmic Calf serum medium, $1 \%$ penicillin/ streptomycin, and $0.01 \%$ gentamicin). Experiments were repeated five times.

In order to determine if the transcription factors studied were direct targets of Ang II, H295R cells were pre-treated with $35 \mu \mathrm{M}$ cycloheximide for $30 \mathrm{~min}$, followed by treatment with $10 \mathrm{nM}$ Ang II for $1 \mathrm{~h}$. RNA was isolated from these cells and used for microarray analysis.

For analysis of Ang II intracellular signaling pathways, H295R cells were sub-cultured onto 24-well dishes at a density of $2 \times 10^{5}$ cells/well. For experiments cells were incubated for $30 \mathrm{~min}$ with the following cell signaling inhibitors: $10 \mu \mathrm{M}$ PD98059 (ERK1/2 inhibitor), $1 \mu \mathrm{M}$ GFX (or GF103209X - PKC inhibitor), $3 \mu \mathrm{M}$ KN93 (CAMK inhibitor), SRC-I (SRC inhibitor), and $50 \mu \mathrm{M}$ AG490 (JAK2 inhibitor), $10 \mu \mathrm{M}$ losartan (AT1R inhibitor), $10 \mu \mathrm{M}$ PD123319 (AT2R inhibitor). The inhibitors' concentrations were selected based on 
screening experiments where three different concentrations were tested on H295R cells. KN93, SRC-I, AG490, and PD98059 were purchased from Calbiochem (Gibbstown, NJ, USA); Losartan (DUP753) was purchased from DuPont Pharmaceutical (Wilmington, DE, USA); PD123319 was purchased from SigmaAldrich; and GFX was purchased from Invitrogen. After pre-treatment with inhibitors, cells were treated with $10 \mathrm{nM}$ Ang II for 1 or $6 \mathrm{~h}$.

\section{Microarray analysis}

RNA from H295R cells was hybridized to an Affymetrix human HG_U133+2 oligonucleotide microarray set containing 54675 probe sets representing $\sim 40500$ independent human genes. The arrays were scanned at high resolution in the microarray core facility at the Medical College of Georgia in Augusta, GA. Results were analyzed using GeneSpring software version 7.3 (Silicon Genetics, Redwood City, CA, USA) to identify differences in gene expression after incubation with cycloheximide (30 min) followed by Ang II (1 h) compared with cycloheximide (30 min) alone.

\section{Adrenal cell transfection}

H295R cells were transfected using Transfast reagent (Promega Corporation) following the manufacturer's protocols. The pGL3-basic (pGL3b) plasmids of $1 \mu \mathrm{g}$ containing luciferase reporter vectors linked to the promoter region of each of the steroidogenic enzymes involved in aldosterone synthesis, namely: StAR, CYP11A1, CYP21A2, HSD3B2, or CYP11B2, was used for each transfection experiment. The pGL3b vectors were individually co-transfected with $0 \cdot 1 \mu \mathrm{g}$ of the following transcription factors: ATF3, EGR1, NGFI-B, NURR-1, or NOR-1 in pCMV-XL5; and FOS, FOSB, or JUNB in pcDNA3.1-zeo. All experiments were repeated a minimum of five times.

In addition, H295R cells were co-transfected with combinations of transcription factors. In these experiments, $1 \mu \mathrm{g}$ of the reporter vectors for the enzymes investigated in our study (StAR, CYP11A1, HSD3B2, CYP21A2, and CYP11B2) was co-transfected with different combinations of expression vectors for the transcription factors using a dose of $0 \cdot 1 \mu \mathrm{g}$ for each expression vector. In this study, the expression vector for JUNB was co-transfected with the expression vector for FOS, FOSB, or ATF3.

In the DN-NGFI-B and NURR-1 co-transfection study, H295R cells were co-transfected under similar conditions with the following doses: $0 \cdot 1 \mu \mathrm{g}$ of NURR-1, $0.5 \mu \mathrm{g}$ of DN-NGFI-B vectors, and $1 \mu \mathrm{g}$ of CYP11B2 reporter vector.

\section{Luciferase-mediated bioluminescence assay}

Cell lysate from transfected H295R cells was plated in a $20 \mu \mathrm{l} /$ well volume followed by immediate addition of $50 \mu \mathrm{l}$ of the luciferase reagent (Promega Corporation) following the manufacturer's instructions. Microplate was read using the FLUOstar Optima instrument (BMG Labtech, Durham, NC, USA). The empty vector containing pGL3b was used as control to normalize the measurements of luciferase activity.

\section{RNA extraction, cDNA synthesis, and real-time RT-PCR}

Total RNA was extracted using the RNeasy kit (Qiagen) according to protocols from the manufacturer. Purity and integrity of the RNA were checked spectroscopically using Nanodrop instrument (NanoDrop Technologies, Wilmington, DE, USA). Total RNA was reverse transcribed using the high-capacity cDNA archive kit (Applied Biosystems, Foster City, CA, USA). Primers for the amplification of the target sequences were designed using Primer Express 3.0 (Applied Biosystems). Primer sequences for the transcription factors used in this study are listed in the supplementary data of our previous article (Nogueira et al. 2007). The DN-NGFI-B primer sequences were F: $5^{\prime}$-CGACCTGCTCTCCG GTTCT-3', R: 5'-CAGCAAAGCCAGGGATCTTC-3'. PCR amplifications were performed using the ABI 7500 Fast Real-Time PCR System (Applied Biosystems) following the reaction parameters recommended by the manufacturer, using $20 \mu \mathrm{l}$ total volume consisting of Fast Reagent Master Mix (Applied Biosystems), primers/probes mix, and cDNA. The gene 18S (Applied Biosystems) was used as the normalization gene. Negative controls contained water instead of cDNA.

In all experiments, the relative gene expression was calculated by the $C_{\mathrm{t}}$ method. Briefly, the resultant mRNA was normalized to a calibrator; in each case, the calibrator chosen was the basal sample. Final results were expressed as $n$ fold difference in gene expression relative to $18 \mathrm{~s}$ rRNA and calibrator as follows: $n$ fold $=2^{-\left(\Delta C_{\mathrm{t}} \text { sample }-\Delta C_{\mathrm{t}} \text { calibrator }\right)}$, where $C_{\mathrm{t}}$ values of the sample and calibrator were determined by subtracting the average $C_{\mathrm{t}}$ value of the transcript under investigation from the average $C_{\mathrm{t}}$ value of the $18 \mathrm{~s}$ rRNA gene for each sample.

\section{Aldosterone measurement}

Aldosterone content of the medium recovered from each well was determined with aldosterone standards prepared in low-serum medium using aldosterone RIAs (Siemens, Los Angeles, CA, USA). Results of aldosterone essay were normalized to cellular protein and expressed as pmol per mg cell protein. 


\section{Statistical analysis}

All values were expressed as a mean \pm s.E.M. One way ANOVA was used to compare groups in the transfection study as well as in the inhibitor study. $P$ values lower than 0.05 were considered statistically significant.

\section{Results}

\section{Ang II directly induces expression of transcription factors}

Inhibition of protein synthesis by pre-incubating H295R cells with cycloheximide $(35 \mu \mathrm{M})$ allowed us to better define the direct versus indirect Ang II gene targets. In the presence of CX, Ang II (10 nM) treatment for $1 \mathrm{~h}$ increased the expression of ATF3, EGR1, FOS, FOSB, JUNB, NGFI-B, NURR-1, and NOR-1 (Fig. 1) as was previously observed in the absence of cycloheximide (Nogueira et al. 2007). These data suggest that these genes are direct targets of Ang II in H295R cells.

\section{Effects of transcription factors on aldosterone synthesis pathway}

\section{AP-1 complex}

Members of the AP-1 complex are known to regulate gene transcription as homo- or heterodimers with members of its own family (Mukai et al. 1998). In the

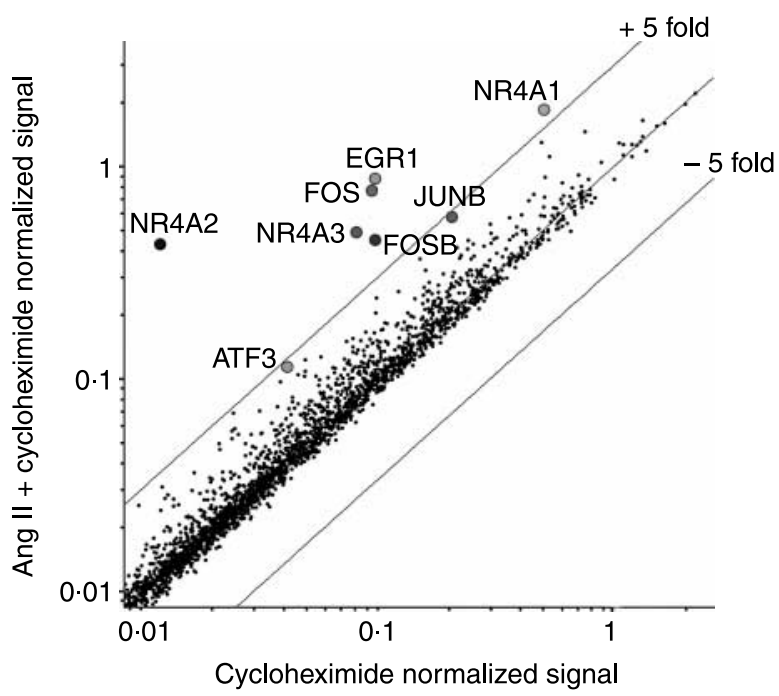

Figure 1 Microarray scatter plot for Ang II plus cycloheximide vs cycloheximide alone. Total RNA was isolated from H295R cells that were incubated with $35 \mu \mathrm{M}$ cycloheximide alone or followed by a combination with $10 \mathrm{nM}$ Ang II for $1 \mathrm{~h}$. Labeled genes represent the transcription factors previously shown to be commonly up-regulated by Ang II treatment in human, bovine, and rat adrenocortical cells (Nogueira et al. 2007). present study, H295R cells were co-transfected with vectors for each individual member of the AP-1 complex and the reporter vectors for StAR, CYP11A1, HSD3B2, CYP21A2, and CYP11B2. The significance was determined by comparing the promoter activity in the presence of the empty vector, pDNA3.1zeo, to the promoter activity in the presence of the transcription factor. In Fig. 2A and B, we demonstrate that FOS and FOSB caused a reduction of $\sim 50 \%$ in the promoter activity of CYP21A2. No other significant effects were observed.

Co-transfection of JUNB alone did not significantly change the promoter activity of the enzymes tested in our study. However, the combination of JUNB with FOS caused an approximate twofold increase in StAR and a $65 \%$ decrease in CYP21A2 promoter activity. Similar effects were seen with a combination of JUNB with FOSB, which increased the promoter activity of StAR by twofold and decreased the promoter activity of CYP21A2 by $85 \%$. JUNB and FOSB also decreased CYP11B2 reporter activity by $70 \%$ (Fig. 2A and B).

\section{ATF3 and EGR1}

The transfection of H295R cells with expression vector for ATF3 did not significantly change the promoter activity of StAR, CYP11A1, CYP21A2, HSD3B2, or CYP11B2. Because ATF3 is known to heterodimerize
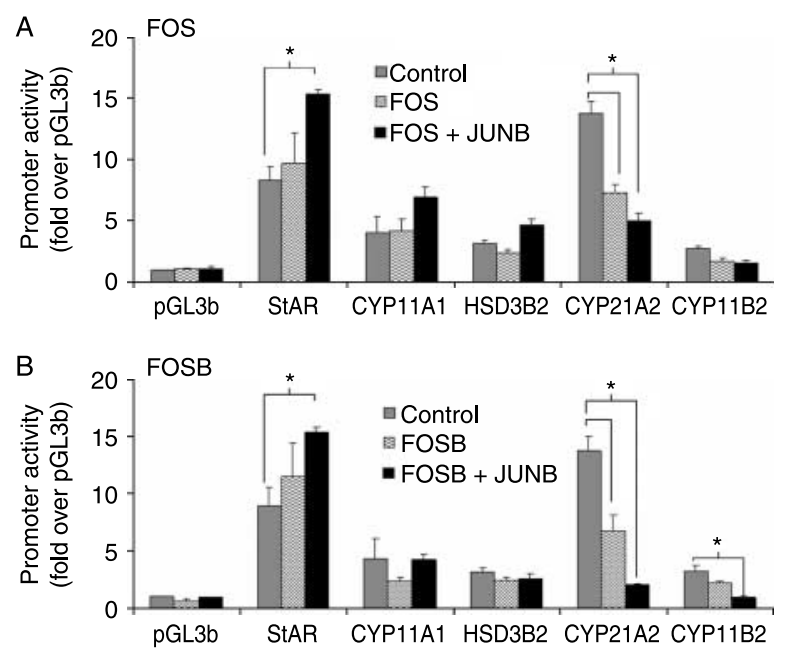

Figure 2 Effects of AP-1 complex members (FOS and FOSB) on the promoter activity of the genes encoding the enzymes involved in aldosterone synthesis. H295R cells were co-transfected with each transcription factor $(0 \cdot 1 \mu \mathrm{g} / \mathrm{ml})$ and each of the indicated steroidogenic enzyme promoter/reporter vectors $(1 \mu \mathrm{g} / \mathrm{ml})$. For analysis of significance, comparison was made with the promoter activity in the presence of the control vector (empty vector= pcDNA3.1zeo) shown in gray bars vs promoter activity in the presence of the transcription factor (black bars). Results represent \pm S.E.M. for five independent experiments. $P<0.05$ was considered significant. 
with JUNB (Nilsson et al. 1997), we also carried out co-transfection experiments. Interestingly, co-transfection of ATF3 with JUNB significantly increased the promoter activity of StAR and CYP11A1 by 2- and 3-fold respectively (Fig. 3A).

The role of EGR1 has not been studied for the transcription of adrenal steroidogenic enzymes. Co-transfection of EGR1 with the selected steroidogenic promoters caused a twofold increase in the promoter activity of CYP21A2. However, EGR1 reduced the promoter activity of CYP11B2 by $50 \%$ as shown in Fig. 3B. StAR, CYP11A1, and HSD3B2 were not affected.

\section{NGFI-B family}

H295R cells respond to Ang II acutely with changes in gene transcription including the induction of all members of the NGFI-B family of nuclear hormone receptors (Bassett et al. 2004a, Romero et al. 2004, Kelly et al. 2005, Nogueira et al. 2007). In the present study, H295R cells were co-transfected with NGFI-B, NURR-1, or NOR-1 plasmids and luciferase reporter-vectors linked to the promoter region of StAR, CYP11A1, CYP21A2, HSD3B2, or CYP11B2. In agreement with the sequence analysis, NGFI-B significantly increased promoter activity of HSD3B2, CYP21A2, and CYP11B2 by 2-, 3-, and 5-fold respectively (Fig. 4A); NURR-1 significantly induced promoter activity of these
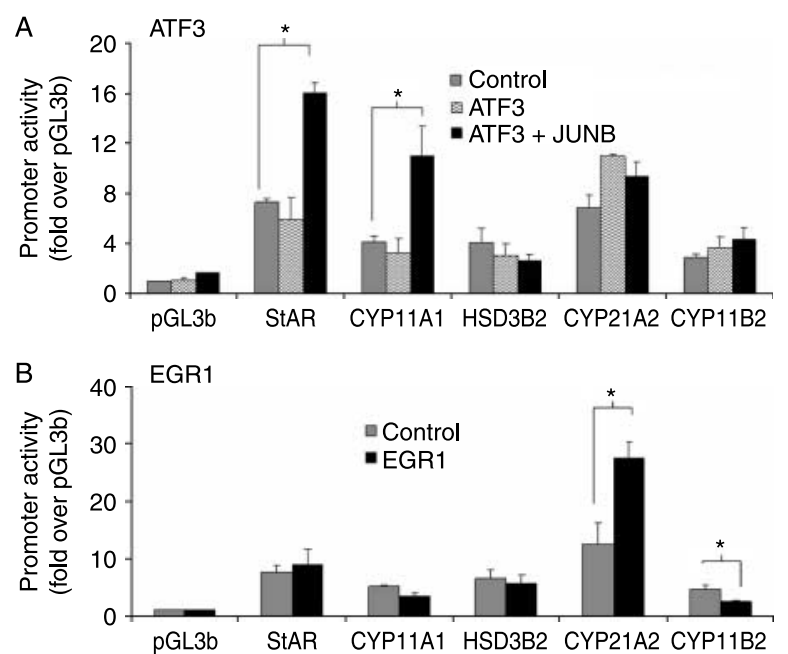

Figure 3 Effects of ATF3 (A) and EGR1 (B) on the promoter activity of the genes encoding the enzymes involved in aldosterone synthesis. H295R cells were co-transfected with each transcription factor $(0.1 \mu \mathrm{g} / \mathrm{ml})$ and each of the steroidogenic enzyme promoter/reporter vectors $(1 \mu \mathrm{g} / \mathrm{ml})$. For analysis of significance, comparison was made with the promoter activity in the presence of the control vector (empty vector $=$ CMV-XL5) shown in gray bars vs promoter activity in the presence of the transcription factor (black bars). Results represent \pm S.E.M. for five independent experiments. $P<0.05$ was considered significant.
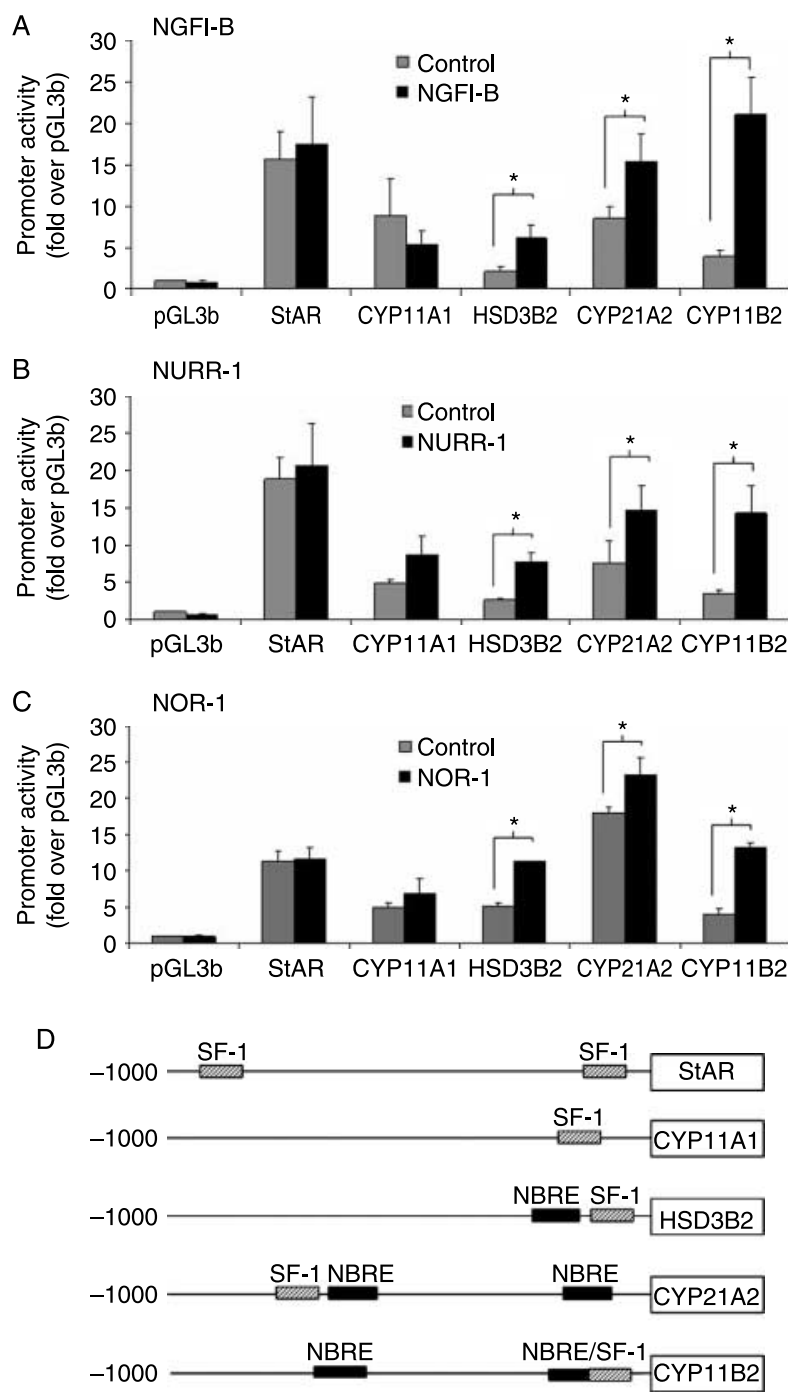

Figure 4 Effects of NGFI-B family members (NGFI-B, NURR-1, NOR-1) on the promoter activity of the genes encoding the enzymes needed for aldosterone synthesis (A, B, and C). H295R cells were co-transfected with each transcription factor $(0.1 \mu \mathrm{g} / \mathrm{ml})$ and each of the steroidogenic enzyme promoter/reporter vectors $(1 \mu \mathrm{g} / \mathrm{ml})$. Identification of NGFI-B and SF-1 binding elements in the promoter region of the genes needed for aldosterone synthesis (D). The consensus DNA NGFI-B binding site is distinguished from the SF-1 binding site by $3 \mathrm{bp}$ located $5^{\prime}$ to the nuclear receptor half-site: A-A-A for NGFI-B and T/A-C/A-A for SF-1. For analysis of significance, comparison was made with the promoter activity in the presence of the control vector (empty vector $=\mathrm{CMV}-\mathrm{XL5}$ ) shown in gray bars vs promoter activity in the presence of the transcription factor (black bars). Results represent \pm S.E.M. for five independent experiments. $P<0.05$ was considered significant.

enzymes by 2-, 3-, and 4-fold respectively (Fig. 4B); and NOR-1 significantly increased promoter activity of the same enzymes by 2-, 2-, and 3-fold respectively (Fig. 4C). An examination of the proximal promoter regions for each of these genes indicated the presence 
of putative NGFI-B binding cis-elements (AAAGGTCA) in CYP21A2, HSD3B2 and CYP11B2 (Fig. 4D). The statistical significance was determined by comparing the promoter activity in the presence of empty vector with the promoter activity in the presence of the transcription factor. These results suggest that NGFI-B family members increase aldosterone production by inducing expression of the enzymes involved in the last three steps of aldosterone synthesis: HSD3B2, CYP21A2, and CYP11B2.

\section{Expression of DN-NGFI-B decreased transcription of CYP11B2}

The truncation present in the activator function 1 (AF-1) domain of the DN-NGFI-B decreases the function of endogenous NGFI-B members through competition for its NGFI-B regulatory element binding site (NBRE; Cheng et al. 1997, Song et al. 2001). DN-NGFI-B H295-TR cells contain a tetracycline responsive system that induces the transcription of this truncated protein after treatment with doxycycline (tetracycline analog). After incubation with doxycycline for $24 \mathrm{~h}$, cells were treated with $10 \mathrm{nM}$ Ang II for $6 \mathrm{~h}$. As shown in Fig. 5A, DN-NGFI-B mRNA levels were sixfold higher in doxycycline treated cells. This increase in
DN-NGFI-B expression was concomitant with a $40 \%$ reduction in CYP11B2 mRNA and a $25 \%$ reduction in aldosterone levels (Fig. 5B and C). Treatment with doxycycline did not affect basal levels of CYP11B2 (Fig. 5B - gray bars). In addition, 11 -hydroxylase (CYP11B1) mRNA levels were not modified by DN-NGFI-B expression (data not shown).

We also used the DN-NGFI-B expression vector to study the regulation of CYP11B2 transcription. In Fig. 5D, transfection of H295R cells with NURR-1 expression vector induced a sevenfold increase in the promoter activity of CYP11B2 in comparison to its empty vector (CMV-XL5). However, when NURR-1 was co-transfected with the DN-NGFI-B expression vector, activity of CYP11B2 was reduced by $68 \%$ in comparison to control levels (NURR-1 + vector only).

\section{Ang II signaling pathways that regulate NGFI-B family}

Ang II activates several intracellular signaling cascades that modulate cellular function. It has been documented that Ang II regulates aldosterone production through AT1R, PKC, CaMK, and SRC signaling pathways (Spat \& Hunyady 2004). Here, we investigated signaling pathways that regulate Ang II induction of NGFI-B family members. Figure 6 shows the mRNA
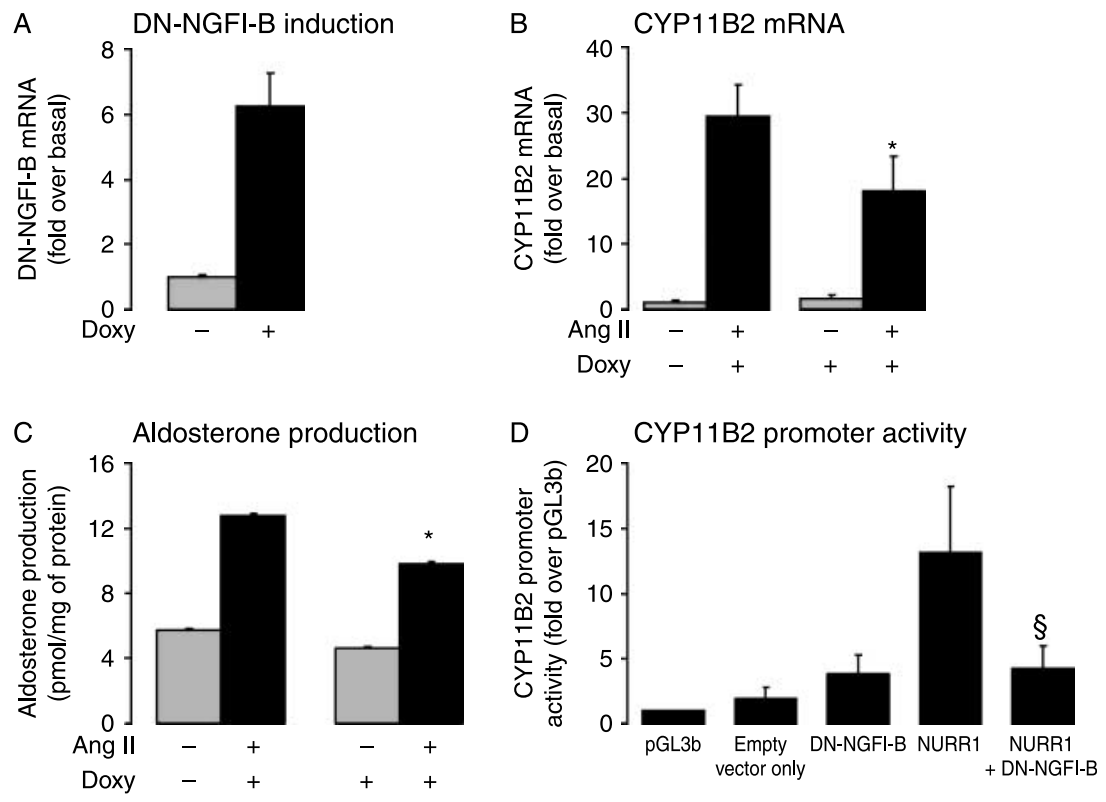

Figure 5 Effects of DN-NGFI-B on CYP11B2 expression and aldosterone production in H295R cells. Panel A) Doxycycline $(2.5 \mu \mathrm{g} / \mathrm{ml})$ induction of DN-NGFI-B mRNA. Panel B) Ang II (10 nM) effects on CYP11B2 mRNA levels with and without induction of DN-NGFI-B. Panel C) Ang II effects on aldosterone production with or without induction of DN-NGFI-B. D) Effects of DN-NGFI-B on NURR-1 stimulated CYP11B2 promoter activity. Fold change was calculated considering pGL3b as control. Empty vector only $=p G L 3 b+p c D N A 3.1 z e o$. For all panels the results represent \pm S.E.M. for four independent experiments. $P<0.05$ was considered significant. 

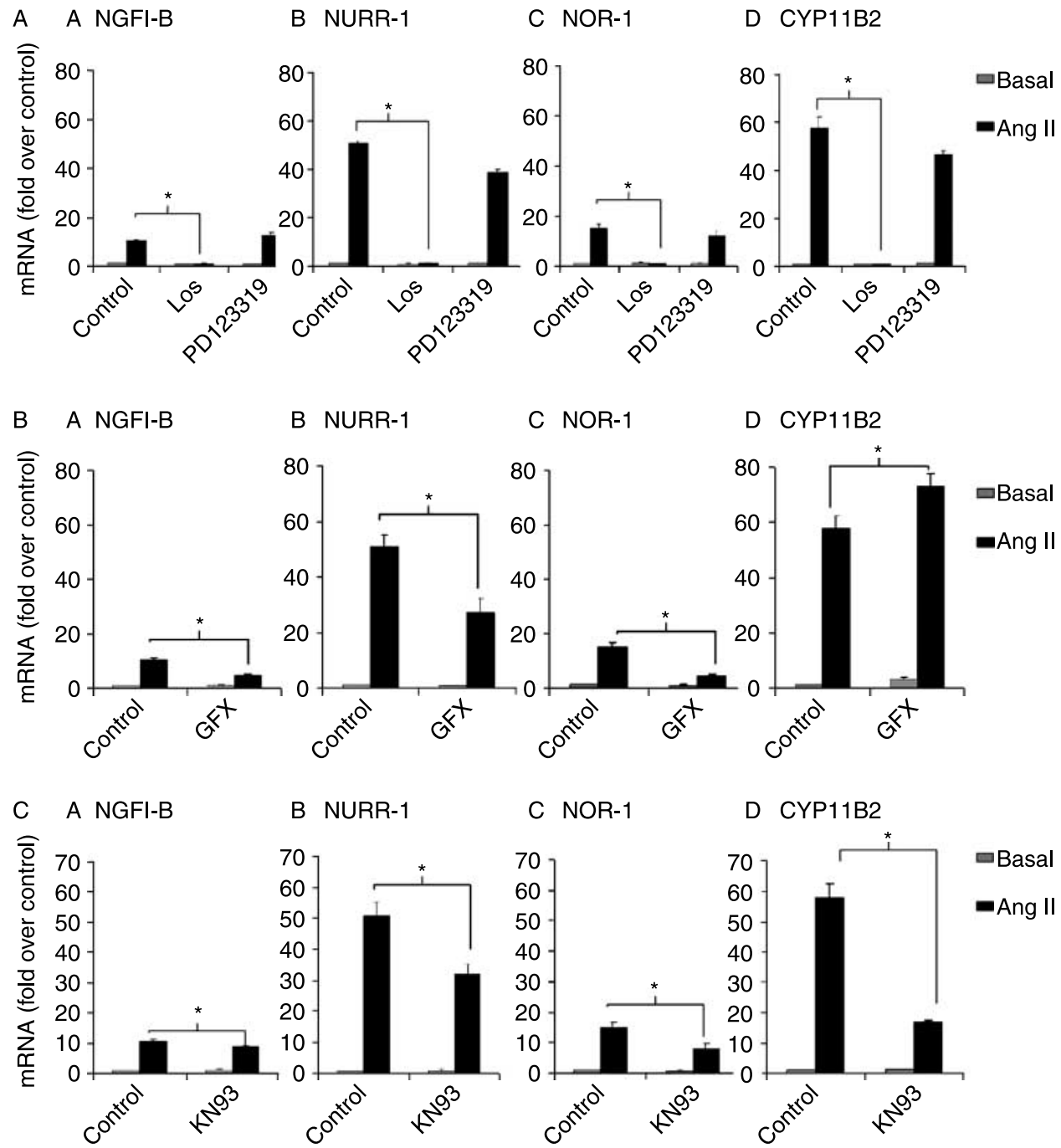

C NOR-1 D CYP11B2
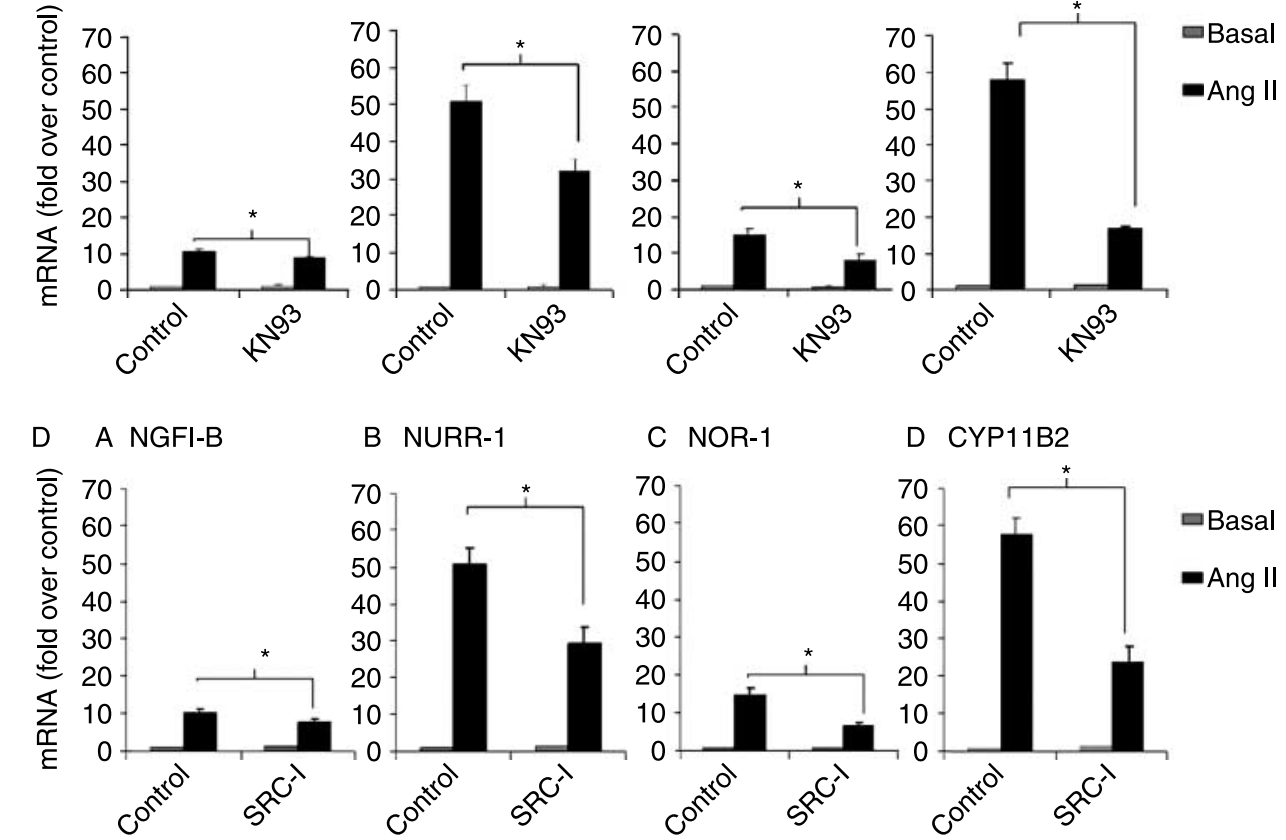

Figure 6 Investigation of Ang II-activated signaling pathways that regulate expression of the NGFI-B family members and CYP11B2. H295R cells were pre-treated with inhibitors for $30 \mathrm{~min}$ followed by Ang Il incubation for $1 \mathrm{~h}$. Transcript levels for NGFI-B, NURR-1, NOR1 and CYP11B2 were measured using qPCR. LOS (losartan=AT1R inhibitor); PD123319 (AT2R inhibitor), GFX (or GF103209X= PKC inhibitor); KN93 (CaMK inhibitor); SRC-I (SRC inhibitor). ${ }^{*}=P<0.05$ (in Ang II-treated cells in the presence vs absence of inhibitors). Results represent \pm S.E.M. for five independent experiments. $P<0.05$ was considered significant. 
levels for NGFI-B members and CYP11B2 after Ang II-incubation for $1 \mathrm{~h}$ in the presence (black bars) or absence (gray bars) of selective inhibitors of Ang II intracellular signaling pathways. As seen in Fig. 6A, inhibition of AT1R signaling by losartan reduced transcription of the three members of NGFI-B family and CYP11B2 to basal levels; whereas PD123319 (AT2R blocker) did not significantly change the expression of these genes. As shown in Fig. 6B, PKC inhibition by GFX reduced the mRNA levels of NGFI-B members by more than $50 \%$. In contrast, this inhibitor caused a small but significant 1.25 fold increase in CYP11B2 transcription. Inhibition of CaMK caused a significant reduction of $\sim 20 \%$ in NGFI-B, $40 \%$ in NURR-1 and NOR-1, and 70\% in CYP11B2 mRNA levels. Inhibition of SRC signaling with SRC-I was also able to significantly decrease expression of NGFI-B (20\%), NURR-1 $(50 \%)$, NOR-1 (50\%), and CYP11B2 (60\%). Inhibition of JAK2 signaling (using AG490) and ERK1/2 (using PD98059) did not significantly change expression of CYP11B2 in our study (data not shown). Finally, alterations in aldosterone production were found to correlate well with inhibitor effects on CYP11B2 mRNA expression (data not shown).

\section{Discussion}

One of the chronic actions of Ang II is its ability to increase the capacity for aldosterone biosynthesis in the adrenal cortex. This occurs through an increase in the proteins need for aldosterone synthesis including StAR, CYP11A1, HSD3B2, CYP21A2, and CYP11B2. The transcription of these genes is regulated through the activation of signaling cascades that influence the activity of already present transcription factors as well as by increasing expression of new transcription factors. We recently defined a group of transcription factors that are rapidly induced following Ang II treatment of adrenocortical cells. In the current study, we demonstrated that these genes are direct targets of Ang II. In addition, we assessed the function of these factors in the transcriptional control of genes encoding the steroidogenic enzymes needed for aldosterone production (Fig. 7).

AP-1 complex transcription factors have been shown to play a role in the trophic effects of Ang II in several tissues including the adrenal cortex (Watanabe et al. 1996, Suzuki et al. 2003, Hattori et al. 2007). The induction of AP-1 complex members by Ang II in

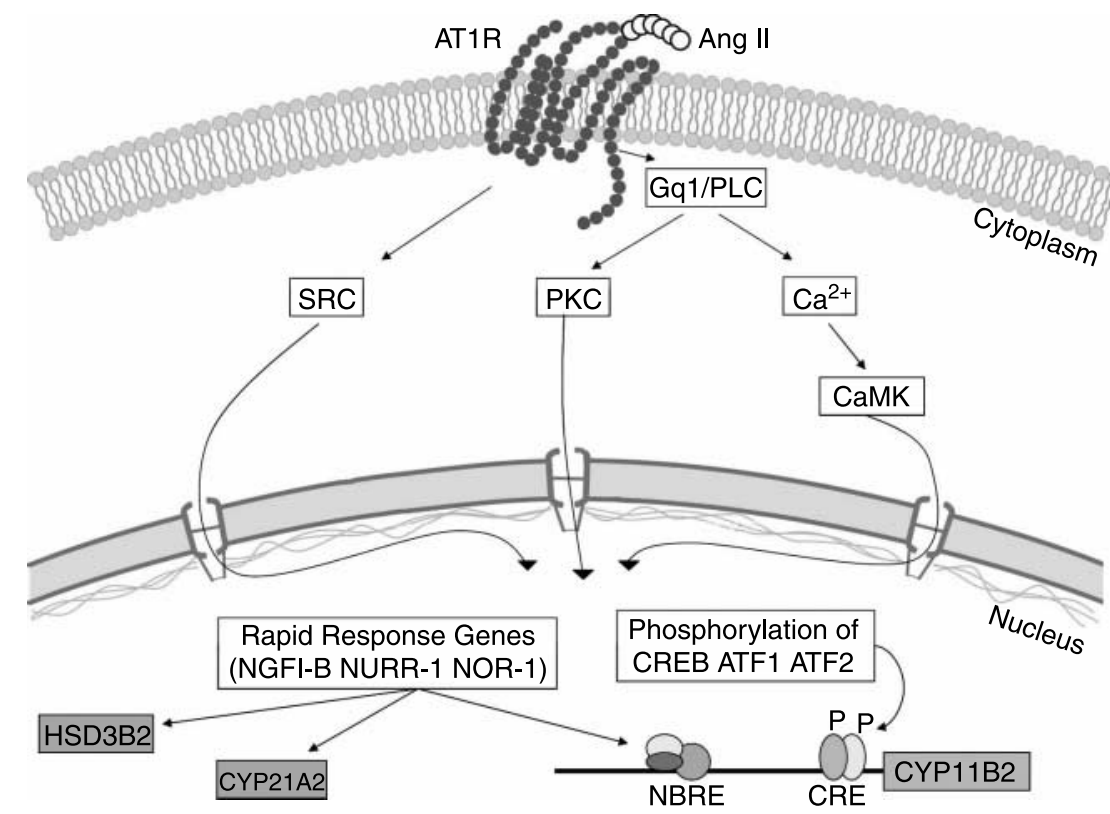

Figure 7 Schematic of Ang II induction of aldosterone production by adrenal glomerulosa cells. Ang II binding to its type 1 receptor (AT1R) activates diverse intracellular signaling pathways, including Src kinase (SRC), protein kinase C (PKC), and calcium-dependent calmodulin kinases (CaMK). This cascade of events induces transcription of rapid response genes such as members of the NGFI-B family, which act as transcription factors for downstream genes including those that are needed for aldosterone synthesis: HSD3B2, CYP21A2, and CYP11B2. These kinases may also phosphorylate and activate several other transcription factors already present in the cell, such as the activator factor 1 and 2 (ATF1, ATF2), and the cAMP-response element binding protein (CREB). Physiologically, Ang II action on the adrenal culminates with increased size and capacity of the zona glomerulosa to produce aldosterone. 
adrenal cells and their role in adrenal steroidogenesis have also been reported previously (Naville et al. 2001, Guo et al. 2007, Romero et al. 2007). Importantly, members of this family commonly need to homo- and/ or heterodimerize among themselves or with other transcription factors to induce transcription (Mukai et al. 1998, Guo et al. 2007). In the present study, we investigated the effect of FOS, FOSB, and JUNB individually and in combination (FOS $+J U N B$ or FOSB + JUNB) on the promoter activity of selected steroidogenic enzymes. A previous study of these genes using transfection of H295R cells suggested a greater role of the AP-1 members in CYP11B1 (Romero et al. 2007). This observation is supported by the presence of a putative AP-1 site in the CYP11B1 but not CYP11B2 gene promoter region (Mukai et al. 1995, Rainey 1999). In our study, AP-1 members alone had no significant effect on genes needed for aldosterone production with the exception of an inhibition of CYP21A2. However, combination of these vectors $(\mathrm{FOS}+\mathrm{JUNB}$ and FOSB + JUNB) stimulated the promoter activity of StAR (early regulatory step in aldosterone production). Intriguingly, the combination of FOS and JUNB further decreased the promoter activity of CYP21A2 when compared with the effect of FOS and FOSB alone. In summary, it is important to consider that the ratios of AP-1 complex members may be important in determining the ultimate cellular phenotype and the role of these transcription factors in steroidogenesis.

Although other members of the ATF family, such as ATF1 and ATF2, have been implicated in the regulation of CYP11B2 (Bassett et al. 2000, Wang et al. 2000), the effects of ATF3 on the genes needed for aldosterone synthesis have not been described previously. Herein, we investigated the effects of ATF3 alone and in combination with JUNB, since these two transcription factors have been shown to interact (Nilsson et al. 1997). Interestingly, this combination resulted in a stimulatory effect of the genes needed to complete the early steps of aldosterone synthesis, specifically StAR and CYP11A1. Once again, the ratios of transcription factors stimulated by Ang II are likely to be important in determining the steroidogenic enzyme expression pattern in adrenocortical cells. Further studies will be needed to define the binding sites that are involved in ATF3 regulation of these genes.

EGR1 has been extensively studied with regard to its role in cell growth and proliferation (Cao et al. 1990, Zhu et al. 2007). Despite the stimulatory effect of the EGR2 isoform on CYP11B2, Romero et al. (2007) Romero and colleagues reported no effect of EGR1 on CYP11B2 gene. We observed that, although EGR1 stimulated CYP21A2 transcription, it decreased CYP11B2 promoter activity. In other tissues, EGR1 synergizes with SF-1 to stimulate LH expression in gonadotrope cells (Dorn et al. 1999). SF-1 has been shown to inhibit CYP11B2 expression in adrenocortical cells (Bassett et al. 2002, Li et al. 2004, Shibata et al. 2004, Ye et al. 2008). Thus, the possibility of interaction between these two proteins may provide a potential mechanism contributing to zonespecific repression of CYP11B2.

Among the eight transcription factors studied, the three members of the NGFI-B family (NGFI-B, NURR-1, and NOR-1) up-regulated the transcription of genes responsible for the last three steps in aldosterone production: HSD3B2, CYP21A2, and CYP11B2. We investigated the presence of NBRE sites in the promoter regions of the enzymes needed for aldosterone synthesis. As shown in Fig. 4D, HSD3B2, CYP21A2, and CYP11B2 were the only enzymes involved in aldosterone biosynthesis that have consensus NBRE sites in their proximal promoter regions. This fact may explain the ability of the NGFI-B family to selectively stimulate the promoter activity of these genes. The present study confirms previous reports that indicated a role of the NGFI-B family in the regulation of adrenalspecific gene expression in vitro and in vivo (Crawford et al. 1995, Fernandez et al. 2000, Bassett et al. 2004a). Bassett et al. (2004b) have described the binding of NGFI-B and NURR-1 to the NBRE and Ad5 cis-elements present in the $5^{\prime}$-flanking region of hCYP11B2. This study further demonstrated the selective effects of these transcription factors on the transcription of HSD3B2 and CYP11B2, whereas no effect was observed on the transcription of CYP11B1 or CYP17. The NGFI-B members have also been reported by Romero et al. (2007) to have a stimulatory effect on CYP11B2 expression in H295R cells. Earlier studies suggested that NGFI-B (Nurr77 in mice) could regulate transcription of mouse CYP21A2 (Wilson et al. 1993, Chang \& Chung 1995). However, mice deficient in NGFI-B appeared to have similar adrenal responses and expression of CYP21A2 to that seen in wild-type mice (Crawford et al. 1995). Interpretation of this study is complicated by the possible compensation by other members of the NGFI-B family in mouse adrenocortical function (Crawford et al. 1995). To address this concern, we used a DN form of NGFI-B that blocks transcriptional activity of all NGFI-B family members (Cheng et al. 1997, Song et al. 2001). Expression of DN-NGFI-B in H295R cells decreased the ability of Ang II to maximally stimulate aldosterone production and CYP11B2 transcription. However, DN-NGFI-B did not completely block Ang II stimulation. Partial effects may be due to: 1) the relatively low induction level of DN-NGFI-B (sixfold) compared to 30-fold induction of endogenous NGFI-B members by Ang II or 2) the NGFI-B-independent induction of CYP11B2 transcription, which occurs due to activation of already present CREB and ATF1 (Bassett et al. 2000, 2004c). Thus, the NGFI-B family likely plays an important role in aldosterone production by the adrenals but it is likely 
that these transcription factors represent only one of several ways that Ang II increases the capacity to produce aldosterone.

The mechanisms through which Ang II regulates the expression of NGFI-B family members have not been well understood. Here, we showed for the first time that Ang II induction of NGFI-B family members occurred uniquely through the AT1R. Similarly, Ang II regulation of CYP11B2 transcription occurred through stimulation of the AT1R in H295R cells. Inhibition of PKC, SRC, as well as calcium signaling through CaMK, was able to partially reduce the expression of NGFI-B members. Inhibition of CaMK also partially blocked the expression of CYP11B2. The role of CaMK in aldosterone synthesis has been previously shown in H295R cells (Pezzi et al. 1997, Condon et al. 2002). SRC has been suggested to regulate aldosterone production by stimulation of HSD3B2 and inhibition of 17 $\alpha$-hydroxylase (Sirianni et al. 2001). Here, we reported for the first time that SRC signaling may regulate aldosterone production through the induction of CYP11B2.

The interpretation of PKC data is complicated by the large number of PKC family members that respond differently to the GFX compound. In addition, adrenal cell activation of different PKC isoforms is known to differentially regulate aldosterone synthesis (LeHoux \& Lefebvre 1998, 2006). Interestingly, in our study, inhibition of PKC by GFX caused a small increase in CYP11B2 expression, a result that agrees with those of LeHoux et al. (2001). This group has also reported that diacylglycerol-regulated PKC can suppress whereas the atypical PKC lambda can enhance the basal expression of CYP11B2 in H295R cells. Thus, the role of PKC isoforms in the regulation of gene expression is likely to be complicated by contrasting actions of different isoforms. Future studies including knockdown of selected PKC isoforms with techniques such as siRNA, may provide important information regarding the role of PKC in aldosterone synthesis.

Using adrenocortical cells, we have shown that large numbers of genes are increased within a short time of Ang II stimulation. Acutely, Ang II increases the expression of hundreds of genes, most of which have not been studied with regard to adrenal function. Our study confirms and extends previous reports related to the role of acutely responsive transcription factors in adrenal steroidogenesis, including the NGFI-B family that appears to increase expression of enzymes involved in aldosterone biosynthesis. In addition, we provide a broad examination of the role of these transcription factors in the transcription of all the genes needed for the synthesis of aldosterone. Based on the current study, Fig. 7 provides a summary of the molecular mechanisms involved in the regulation of aldosterone synthesis. Further studies that focus on the interactions between Ang II responsive transcription factors and those already present will help to better understand the mechanisms controlling the capacity of the adrenal to produce aldosterone.

\section{Declaration of interest}

The authors declare that there is no conflict of interest that would prejudice the impartiality of this scientific work.

\section{Funding}

This work was supported by National Institute of Health grant DK43140 to WER.

\section{References}

Adler GK, Chen R, Menachery AI, Braley LM \& Williams GH 1993 Sodium restriction increases aldosterone biosynthesis by increasing late pathway, but not early pathway, messenger ribonucleic acid levels and enzyme activity in normotensive rats. Endocrinology 133 2235-2240.

Bassett MH, Zhang Y, White PC \& Rainey WE 2000 Regulation of human CYP11B2 and CYP11B1: comparing the role of the common CRE/Ad1 element. Endocrine Research 26 941-951.

Bassett MH, Zhang Y, Clyne C, White PC \& Rainey WE 2002 Differential regulation of aldosterone synthase and 11betahydroxylase transcription by steroidogenic factor-1. Journal of Molecular Endocrinology 28 125-135.

Bassett MH, Suzuki T, Sasano H, White PC \& Rainey WE $2004 a$ The orphan nuclear receptors NURR1 and NGFIB regulate adrenal aldosterone production. Molecular Endocrinology 18 279-290.

Bassett MH, White PC \& Rainey WE 2004b A role for the NGFI-B family in adrenal zonation and adrenocortical disease. Endocrine Research 30 567-574.

Bassett MH, White PC \& Rainey WE 2004c The regulation of aldosterone synthase expression. Molecular and Cellular Endocrinology 217 67-74.

Betancourt-Calle S, Calle RA, Isales CM, White S, Rasmussen H \& Bollag WB 2001 Differential effects of agonists of aldosterone secretion on steroidogenic acute regulatory phosphorylation. Molecular and Cellular Endocrinology 173 87-94.

Bird IM, Pasquarette MM, Rainey WE \& Mason JI 1996 Differential control of 17 alpha-hydroxylase and 3 beta-hydroxysteroid dehydrogenase expression in human adrenocortical H295R cells. Journal of Clinical Endocrinology and Metabolism 81 2171-2178.

Bird IM, Mason JI \& Rainey WE 1998 Protein kinase A, protein kinase $\mathrm{C}$, and $\mathrm{Ca}(2+)$-regulated expression of 21-hydroxylase cytochrome P450 in H295R human adrenocortical cells. Journal of Clinical Endocrinology and Metabolism 83 1592-1597.

Cao XM, Koski RA, Gashler A, McKiernan M, Morris CF, Gaffney R, Hay RV \& Sukhatme VP 1990 Identification and characterization of the Egr-1 gene product, a DNA-binding zinc finger protein induced by differentiation and growth signals. Molecular and Cellular Biology 10 1931-1939.

Chabre O, Cornillon F, Bottari SP, Chambaz EM \& Vilgrain I 1995 Hormonal regulation of mitogen-activated protein kinase activity in bovine adrenocortical cells: cross-talk between phosphoinositides, adenosine $3^{\prime}, 5^{\prime}$-monophosphate, and tyrosine kinase receptor pathways. Endocrinology 136 956-964.

Chang SF \& Chung BC 1995 Difference in transcriptional activity of two homologous CYP21A genes. Molecular Endocrinology 9 1330-1336. 
Cheng LE, Chan FK, Cado D \& Winoto A 1997 Functional redundancy of the Nur77 and Nor-1 orphan steroid receptors in T-cell apoptosis. EMBO Journal 16 1865-1875.

Cherradi N, Rossier MF, Vallotton MB, Timberg R, Friedberg I, Orly J, Wang XJ, Stocco DM \& Capponi AM 1997 Submitochondrial distribution of three key steroidogenic proteins (steroidogenic acute regulatory protein and cytochrome p450scc and 3betahydroxysteroid dehydrogenase isomerase enzymes) upon stimulation by intracellular calcium in adrenal glomerulosa cells. Journal of Biological Chemistry 272 7899-7907.

Clark BJ, Pezzi V, Stocco DM \& Rainey WE 1995 The steroidogenic acute regulatory protein is induced by angiotensin II and $\mathrm{K}^{+}$in H295R adrenocortical cells. Molecular and Cellular Endocrinology 115 215-219.

Clyne CD, Zhang Y, Slutsker L, Mathis JM, White PC \& Rainey WE 1997 Angiotensin II and potassium regulate human CYP11B2 transcription through common cis-elements. Molecular Endocrinology 11 638-649.

Condon JC, Pezzi V, Drummond BM, Yin S \& Rainey WE 2002 Calmodulin-dependent kinase I regulates adrenal cell expression of aldosterone synthase. Endocrinology 143 3651-3657.

Cote M, Muyldermans J, Chouinard L \& Gallo-Payet N 1998 Involvement of tyrosine phosphorylation and MAPK activation in the mechanism of action of ACTH, angiotensin II and vasopressin. Endocrine Research 24 415-419.

Crawford PA, Sadovsky Y, Woodson K, Lee SL \& Milbrandt J 1995 Adrenocortical function and regulation of the steroid 21-hydroxylase gene in NGFI-B-deficient mice. Molecular and Cellular Biology 15 4331-4336.

Doghman M, Karpova T, Rodrigues GA, Arhatte M, De Moura J, Cavalli LR, Virolle V, Barbry P, Zambetti GP, Figueiredo BC et al. 2007 Increased steroidogenic factor-1 dosage triggers adrenocortical cell proliferation and cancer. Molecular Endocrinology 21 2968-2987.

Dorn C, Ou Q, Svaren J, Crawford PA \& Sadovsky Y 1999 Activation of luteinizing hormone beta gene by gonadotropin-releasing hormone requires the synergy of early growth response- 1 and steroidogenic factor-1. Journal of Biological Chemistry 274 13870-13876.

Fernandez PM, Brunel F, Jimenez MA, Saez JM, Cereghini S \& Zakin MM 2000 Nuclear receptors Nor1 and NGFI-B/Nur77 play similar, albeit distinct, roles in the hypothalamo-pituitary-adrenal axis. Endocrinology 141 2392-2400.

Guo IC, Huang CY, Wang CK \& Chung BC 2007 Activating protein-1 cooperates with steroidogenic factor-1 to regulate $3^{\prime}, 5^{\prime}$-cyclic adenosine $5^{\prime}$-monophosphate-dependent human CYP11A1 transcription in vitro and in vivo. Endocrinology 148 1804-1812.

Hattori Y, Hattori S, Akimoto K, Nishikimi T, Suzuki K, Matsuoka H \& Kasai K 2007 Globular adiponectin activates nuclear factor-kappaB and activating protein- 1 and enhances angiotensin II-induced proliferation in cardiac fibroblasts. Diabetes 56 804-808.

Hunyady L \& Catt KJ 2006 Pleiotropic AT1 receptor signaling pathways mediating physiological and pathogenic actions of angiotensin II. Molecular Endocrinology 20 953-970.

Kelly SN, McKenna TJ \& Young LS 2005 Coregulatory protein-orphan nuclear receptor interactions in the human adrenal cortex. Journal of Endocrinology 186 33-42.

LeHoux JG \& Lefebvre A 1998 Transcriptional activity of the hamster CYP11B2 promoter in NCI-H295 cells stimulated by angiotensin II, potassium, forskolin and bisindolylmaleimide. Journal of Molecular Endocrinology 20 183-191.

LeHoux JG \& Lefebvre A 2006 Novel protein kinase C-epsilon inhibits human CYP11B2 gene expression through ERK1/2 signalling pathway and JunB. Journal of Molecular Endocrinology 36 51-64.

Lehoux JG, Hales DB, Fleury A, Briere N, Martel D \& Ducharme L 1999 The in vivo effects of adrenocorticotropin and sodium restriction on the formation of the different species of steroidogenic acute regulatory protein in rat adrenal. Endocrinology 140 $5154-5164$.
LeHoux JG, Dupuis G \& Lefebvre A 2001 Control of CYP11B2 gene expression through differential regulation of its promoter by atypical and conventional protein kinase $\mathrm{C}$ isoforms. Journal of Biological Chemistry 276 8021-8028.

Li LA, Chang YC, Wang CJ, Tsai FY, Jong SB \& Chung BC 2004 Steroidogenic factor 1 differentially regulates basal and inducible steroidogenic gene expression and steroid synthesis in human adrenocortical H295R cells. Journal of Steroid Biochemistry and Molecular Biology 91 11-20.

Miura S, Zhang J, Matsuo Y, Saku K \& Karnik SS 2004 Activation of extracellular signal-activated kinase by angiotensin II-induced Gq-independent epidermal growth factor receptor transactivation. Hypertension Research 27 765-770.

Mukai K, Mitani F, Shimada H \& Ishimura Y 1995 Involvement of an AP-1 complex in zone-specific expression of the CYP11B1 gene in the rat adrenal cortex. Molecular and Cellular Biology 15 6003-6012.

Mukai K, Mitani F, Agake R \& Ishimura Y 1998 Adrenocorticotropic hormone stimulates CYP11B1 gene transcription through a mechanism involving AP-1 factors. European Journal of Biochemistry 256 190-200.

Muller J 1995 Aldosterone: the minority hormone of the adrenal cortex. Steroids 60 2-9.

Naville D, Bordet E, Berthelon MC, Durand P \& Begeot M 2001 Activator protein-1 is necessary for angiotensin-II stimulation of human adrenocorticotropin receptor gene transcription. European Journal of Biochemistry 268 1802-1810.

Nilsson M, Ford J, Bohm S \& Toftgard R 1997 Characterization of a nuclear factor that binds juxtaposed with ATF3/Jun on a composite response element specifically mediating induced transcription in response to an epidermal growth factor/Ras/Raf signaling pathway. Cell Growth and Differentiation 8 913-920.

Nogueira EF, Vargas CA, Otis M, Gallo-Payet N, Bollag WB \& Rainey WE 2007 Angiotensin-II acute regulation of rapid response genes in human, bovine, and rat adrenocortical cells. Journal of Molecular Endocrinology 39 365-374.

Peters B, Clausmeyer S, Obermuller N, Woyth A, Kranzlin B, Gretz N \& Peters J 1998 Specific regulation of StAR expression in the rat adrenal zona glomerulosa. An in situ hybridization study. Journal of Histochemistry and Cytochemistry 46 1215-1221.

Pezzi V, Clyne CD, Ando S, Mathis JM \& Rainey WE 1997 Ca(2+)regulated expression of aldosterone synthase is mediated by calmodulin and calmodulin-dependent protein kinases. Endocrinology 138 835-838.

Quinn SJ \& Williams GH 1988 Regulation of aldosterone secretion. Annual Review of Physiology 50 409-426.

Rainey WE 1999 Adrenal zonation: clues from 11beta-hydroxylase and aldosterone synthase. Molecular and Cellular Endocrinology 151 151-160.

Rainey WE, Naville D \& Mason JI 1991 Regulation of 3 betahydroxysteroid dehydrogenase in adrenocortical cells: effects of angiotensin-II and transforming growth factor beta. Endocrine Research 17 281-296.

Romero DG, Plonczynski M, Vergara GR, Gomez-Sanchez EP \& Gomez-Sanchez CE 2004 Angiotensin II early regulated genes in H295R human adrenocortical cells. Physiological Genomics 19 106-116.

Romero DG, Rilli S, Plonczynski MW, Yanes LL, Zhou MY, GomezSanchez EP \& Gomez-Sanchez CE 2007 Adrenal transcription regulatory genes modulated by angiotensin II and their role in steroidogenesis. Physiological Genomics 30 26-34.

Seta K, Nanamori M, Modrall JG, Neubig RR \& Sadoshima J 2002 AT1 receptor mutant lacking heterotrimeric $\mathrm{G}$ protein coupling activates the Src-Ras-ERK pathway without nuclear translocation of ERKs. Journal of Biological Chemistry 277 9268-9277.

Shibata H, Ogishima T, Mitani F, Suzuki H, Murakami M, Saruta T \& Ishimura Y 1991 Regulation of aldosterone synthase cytochrome $\mathrm{P}-450$ in rat adrenals by angiotensin II and potassium. Endocrinology 128 2534-2539. 
Shibata H, Kobayashi S, Kurihara I, Suda N, Yokota K, Murai A, Ikeda Y, Saito I, Rainey WE \& Saruta T 2004 COUP-TF and transcriptional coregulators in adrenal steroidogenesis. Endocrine Research 30 795-801.

Sirianni R, Sirianni R, Carr BR, Pezzi V \& Rainey WE 2001 A role for src tyrosine kinase in regulating adrenal aldosterone production. Journal of Molecular Endocrinology 26 207-215.

Song KH, Park JI, Lee MO, Soh J, Lee K \& Choi HS 2001 LH induces orphan nuclear receptor Nur77 gene expression in testicular Leydig cells. Endocrinology 142 5116-5123.

Spat A \& Hunyady L 2004 Control of aldosterone secretion: a model for convergence in cellular signaling pathways. Physiological Reviews 84 489-539.

Suzuki Y, Ruiz-Ortega M, Lorenzo O, Ruperez M, Esteban V \& Egido J 2003 Inflammation and angiotensin II. International Journal of Biochemistry and Cell Biology 35 881-900.

Thomas WG \& Qian H 2003 Arresting angiotensin type 1 receptors. Trends in Endocrinology and Metabolism 14 130-136.

Tremblay A, Parker KL \& Lehoux JG 1992 Dietary potassium supplementation and sodium restriction stimulate aldosterone synthase but not 11 beta-hydroxylase P-450 messenger ribonucleic acid accumulation in rat adrenals and require angiotensin II production. Endocrinology 130 3152-3158.

Wang XL, Bassett M, Zhang Y, Yin S, Clyne C, White PC \& Rainey WE 2000 Transcriptional regulation of human 11beta-hydroxylase (hCYP11B1). Endocrinology 141 3587-3594.
Watanabe G, Lee RJ, Albanese C, Rainey WE, Batlle D \& Pestell RG 1996 Angiotensin II activation of cyclin D1-dependent kinase activity. Journal of Biological Chemistry 271 22570-22577.

Wei H, Ahn S, Shenoy SK, Karnik SS, Hunyady L, Luttrell LM \& Lefkowitz RJ 2003 Independent beta-arrestin 2 and G proteinmediated pathways for angiotensin II activation of extracellular signal-regulated kinases 1 and 2. PNAS 100 10782-10787.

Wilson TE, Mouw AR, Weaver CA, Milbrandt J \& Parker KL 1993 The orphan nuclear receptor NGFI-B regulates expression of the gene encoding steroid 21-hydroxylase. Molecular and Cellular Biology 13 861-868.

Ye P, Nakamura Y, Lalli E \& Rainey WE 2008 Differential effects of high and low steroidogenic factor-1 expression on CYP11B2 expression and aldosterone production in adrenocortical cells. Endocrinology 150 1303-1309.

Zhu X, Lin Y, Bacanamwo M, Chang L, Chai R, Massud I, Zhang J, Garcia-Barrio MT, Thompson WE \& Chen YE 2007 Interleukin-1 beta-induced Id2 gene expression is mediated by Egr-1 in vascular smooth muscle cells. Cardiovascular Research 76 141-148.

Received in final form 14 December 2008

Accepted 21 January 2009

Made available online as an Accepted Preprint 21 January 2009 